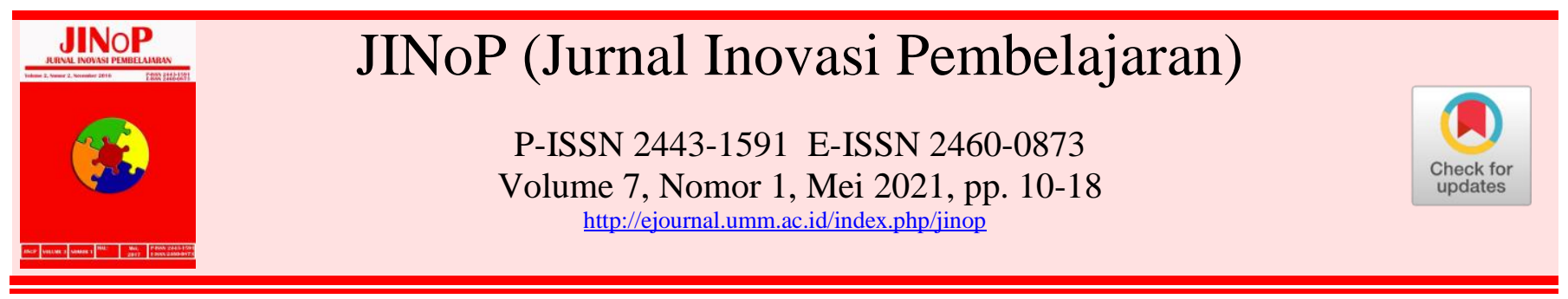

\title{
Kesadaran metakognitif siswa setelah mengikuti pembelajaran modifikasi cooperative script dipadu Hybrid-PjBl
}

\author{
Nurwidodo $^{1)}$, Dini Fithria Nurul Aisyah ${ }^{2)}$, Ahmad Fauzi $^{3)^{*}}$ \\ ${ }^{1}$ Program Studi Pendidikan Biologi, Fakultas Keguruan dan Ilmu Pendidikan, Universitas \\ Muhamamdiyah Malang, Jl. Tlogomas No. 246, Lowokwaru, Kota Malang, Indonesia \\ ${ }^{2}$ SMAN 7 Malang, Jl. Cengger Ayam I No.14, Tulusrejo, Lowokwaru, Kota Malang, Indonesia \\ ${ }^{3}$ Program Studi Pendidikan Biologi, Fakultas Keguruan dan Ilmu Pendidikan, Universitas \\ Muhamamdiyah Malang, Jl. Tlogomas No. 246, Lowokwaru, Kota Malang, Indonesia \\ nurwidodo@umm.ac.id; dinifithria@gmail.com ; ahmad_fauzi@umm.ac.id* \\ *Penulis Koresponden
}

\begin{abstract}
ABSTRAK
Pemberdayaan kesadaran metakognitif termasuk bagian utama dari pembelajaran abad 21. Tujuan penelitian kuantitatif ini adalah untuk mengkaji profil kesadaran metakognitif siswa yang telah mengikuti pembelajaran biologi yang menerapkan strategi modifikasi Cooperative script (CS) dipadu Hybrid-PjB1. Subjek penelitian ini adalah siswa XI IPA SMA 5 Malang. Metacognitive Awareness Inventory digunakan sebagai instrumen pengumpulan data, sedangkan statistik deskriptif dan Pearson Product Momment dipilih sebagai teknik analisis data. Hasil penelitian menginformasikan bahwa $20 \%$ siswa memiliki kesadaran metakognitif berkategori "sangat baik", $40 \%$ siswa berkategori "baik", sedangkan $40 \%$ sisanya berkategori "cukup". Bila dianalisis secara lebih detail, satu komponen metakognisi tergolong "cukup", enam komponen tergolong "baik", sedangkan satu komponen lainnya berkategori "sangat baik". Sebagian besar komponen metakognisi berkorelasi satu sama lain. Hasil penelitian ini mengindikasikan bahwa pembelajaran biologi yang menerapkan modifikasi CS dipadu Hybrid-PjBL berpotensi memberdayakan kesadaran metakognitif siswa.

Kata Kunci: Pembelajaran Hybrid; Kesadaran Metakognitif; Metakognisi Siswa
\end{abstract}

\begin{tabular}{|c|}
\hline ABSTRACT \\
\hline $\begin{array}{l}\text { Empowering students' metacognitive awareness is among the } 21^{\text {st }} \text { century learning strategies. } \\
\text { This research aims to determine the profile of students' metacognitive awareness in Biology } \\
\text { subject through the implementation of Cooperative Script (CS) modification strategy combined } \\
\text { with Hybrid-PjBl. It employed quantitative method with the participants of students from XI IPA } \\
\text { SMA } 5 \text { Malang. The instrument for data collection was Metacognitive Awareness Inventory, with } \\
\text { descriptive statistics and Pearson Product Moment as data analysis techniques. Results show that } \\
20 \% \text { of students' metacognitive awareness was in the "very good" category; } 40 \% \text { of students in } \\
\text { the "good" category; while the remaining } 40 \% \text { were in the "fair" category. Based on more } \\
\text { detailed analyses, one component of metacognition is classified as "fair", six components are } \\
\text { classified as "good", while the rest is classified as "very good". Most metacognition components } \\
\text { are correlated with each other. These findings indicate that Biology learning with CS modification } \\
\text { combined with Hybrid-PjBL potentially empowers students' metacognitive awareness. } \\
\text { Keywords: Hybrid Learning; Metacognitive Awareness; Students' Metacognition }\end{array}$ \\
\hline $\begin{array}{l}\text { diunggah: 2019-11-24, direvisi: 2021-02-18, diterima: 2021-04-11, dipublikasi:2021-05-20 } \\
\text { Copyright (c) } 2020 \text { Nurwidodo et a } \\
\text { This is an open access article under the CC-BY license }\end{array}$ \\
\hline (c) (i) \\
\hline $\begin{array}{l}\text { Cara sitasi: Nurwidodo, N., Aisyah, D.F.N., \& Fauzi, A. (2021). Kesadaran metakognitif siswa } \\
\text { setelah mengikuti pembelajaran modifikasi cooperative script dipadu Hybrid-PjB1. JINoP (Jurnal } \\
\text { Inovasi Pembelajaran), 7(1), 10-18. https://doi.org/10.22219/jinop.v7i1.10376 }\end{array}$ \\
\hline
\end{tabular}




\section{PENDAHULUAN}

Kesadaran metakognitif telah dianggap sebagai variabel penting dalam proses pembelajaran (Millis, 2016; Yanqun, 2019). Metakognisi merupakan faktor yang menentukan tingkat kemampuan seorang siswa untuk memonitor proses berpikir mereka sendiri (Patterson, 2011). Dengan kesadaran metakognitif yang baik, siswa lebih memiliki landasan berpikir tentang apa yang sedang dilakukan dan mengetahui alasan melakukan hal tersebut (Jankowski \& Holas, 2014). Siswa juga terbiasa merencanakan dan mengevaluasi pengalaman belajar dan strategi berpikir yang telah mereka pilih (Patterson, 2011; Thomas, 2014). Siswa akan menyadari keterampilan yang telah dikuasai dan menggunakan keterampilan tersebut pada waktu dan situasi yang tepat (Chauhan \& Singh, 2014). Siswa juga akan mampu memaksimalkan proses belajarnya (Chauhan \& Singh, 2014; Smith, Black, \& Hooper, 2017). Selain itu, mereka akan mampu menyelesaikan tugas dengan baik serta memperoleh capaian akademik yang optimal (Abdellah, 2015).

Sayangnya, banyak guru di Indonesia terindikasi masih jarang menerapkan pembelajaran yang mampu memberdayakan keterampilan metakognitif siswa. Informasi tersebut diperkuat dengan beberapa laporan yang menginformasikan rendahnya keterampilan metakognitif siswa di berbagai sekolah di wilayah Indonesia (Diella \& Ardiansyah, 2017; Nurajizah, Windyariani, \& Setiono, 2018; Susilo, Kartono, \& Mastur, 2019; Tjalla \& Putriyani, 2018; Yanti, Distrik, \& Khasyyatillah, 2017), Padahal, terdapat berbagai bentuk dan inovasi pembelajaran yang terbukti mampu meningkatkan metakognisi siswa. Beberapa teknik pembelajaran yang direkomendasikan untuk digunakan guru dalam memberdayakan metakognisi siswa, antara lain refleksi dan penilaian diri (Colbert et al., 2015; Pedone, 2014), feedback (Colbert et al., 2015), hingga penyusunan peta konsep (Pedone, 2014). Berbagai model pembelajaran pun telah dilaporkan memiliki pengaruh signifikan terhadap metakognisi, antara lain search-solvecreate-share learning model (Yusnaeni \& Corebima, 2017), simas eric (Darmawan, Brasilita, Zubaidah, \& Saptasari, 2018), problem-based learning (Haryani, Masfufah, Wijayati, \& Kurniawan, 2018), project-based learning (PavkovHrvojevic, Obadovic, Cvjeticanin, \& Bogdanovic, 2016), hingga pembelajaran berbasis inquiri (Adnan \& Bahri, 2018). Selain itu, beberapa laporan juga melaporkan potensi cooperative script dalam memberdayakan metakognisi siswa (Ramadani, Fauzi, Sukmawati, \& Corebima, 2015).

Cooperative script (CS) merupakan salah satu bentuk pembelajaran kooperatif. Pembelajaran CS diawali dengan memasangkan setiap siswa, membagi materi menjadi dua bagian, menginstruksikan siswa merangkum bagian merka masing-masing, membacakan hasil rangkuman kepasangannya, dan menyusun rangkuman akhir bersama pasangan. Bila mengkaji tentang dampak dari pelaksanaan pembelajaran kooperatif, maka kita akan mendapatkan banyak dampak positif dari pelaksanaan pembelajaran tersebut. Secara umum, pembelajaran kooperatif merupakan aktivitas terstruktur dalam lingkungan pembelajaran yang bermanfaat untuk meningkatkan potensi belajar yang cocok dan mendalam bagi siswa. Ada beberapa masalah yang dapat menjadi hambatan dalam pelaksanaan pembelajaran kooperatif, yaitu semisal ada siswa yang terlalu mendominasi dalam kegiatan pembelajaran atau ada beberapa siswa yang tidak terlalu ikut berpartisipasi dalam kegiatan pembelajaran (Smith, 1996). Oleh karena 
itu, pemodifikasian CS perlu dilakukan untuk mengoptimalkan bentuk pembelajaran ini.

Di sisi lain, salah satu model pembelajaran yang dilaporkan mampu memberdayakan kompetensi Abad ke-21 secara optimal adalah Project Based Learning atau PjBL (Bell, 2010). Melalui PjBL, mahasiswa akan diarahkan untuk mengikuti pembelajaran secara aktif dan mandiri serta melatih mereka berkolaborasi dan berkomunikasi dengan teman (Kokotsaki, Menzies, \& Wiggins, 2016). PjBL juga dianggap sebagai bentuk pembelajaran yang cocok bagi mahasiswa dalam mempelajari sains, khususnya di era saat ini (Holubova, 2008; Movahedzadeh, Patwell, Rieker, \& Gonzalez, 2012). Pembelajaran ini pun telah dilaporkan memiliki dampak positif pada hasil belajar (Fini, Awadallah, Parast, \& Abu-Lebdeh, 2018), keterampilan berpikir kreatif (Antika \& Nawawi, 2017; Rambely et al., 2013), hingga motivasi belajar mahasiswa (Movahedzadeh et al., 2012).

Pengkajian manfaat penerapan Hybrid-PjBL dalam proses pembelajaran masih perlu dikaji lagi guna mengetahui pengaruh bentuk pembelajaran ini terhadap berbagai parameter lainnya. Pada penelitian ini, model pembelajaran inovatif diterapkan di pembelajaran biologi SMA. Pembelajaran tersebut adalah modifikasi modifikasi cooperative script (CS) yang dipadu oleh Hybrid-PjBl. Hybrid-PjBL dilaporkan dapat menstimulus dan mengembangkan kesadaran metakognitif siswa secara efektif. Studi selanjutnya yang dilakukan oleh Husamah (2015) melaporkan bahwa pengimplementasian Hybrid-PjBL memberikan dampak positif pada keterampilan berpikir mahasiswa.

\section{METODE}

Penelitian ini merupakan penelitian deskriptif kuantitatif yang dilakukan pada tahun 2019 di SMAN 7 Malang yang merupakan SMA unggulan pertama di Kota Malang. Subjek penelitian ini adalah siswa kelas XI IPA 5.

Pembelajaran yang diimplementasikan selam studi ini adalah modifikasi CS yang dipadu dengan hybrid-PjBl. Sintaks pembelajaran modifikasi CS tersebut dimulai dari mengarahkan siswa untuk duduk di kelompok masing-masing, satu kelompok terdiri dari lima orang. Setiap anggota kelompok akan menjelaskan isi dari resume yang telah mereka susun sebelum pembelajaran di mulai. Setiap anggota kelompok mendapatkan jatah topik resume yang berbeda. Setelah anggota lain mendengarkan penjelasan isi resume dari salah satu teman kelompoknnya, mereka bertanya dan berkomentar terkait penjelasan tersebut. Lalu, guru mempersilakan salah satu perwakilan dari salah satu kelompok untuk menjelaskan topik yang telah mereka diskusikan di kelompok masing-masing ke depan kelas. Kemudian, guru mempersilakan kelompok lain bertanya kepada siswa yang telah menjelaskan materi di depan. Di akhir, guru melakukan review terhadap materi yang telah dipelajari oleh siswa.

Dari aspek pengimplementasian $\mathrm{PjBL}$, siswa ditugaskan untuk menciptakan media pembelajaran berdasarkan materi yang telah mereka pelajari selama pembelajaran biologi. Kegiatan tersebut didesain secara hybrid, yaitu gabungan antara tatap muka dan kegiatan daring. Terdapat tiga kali kegiatan tatap muka, yaitu di awal (perancangan desain proyek), di pertengahan kegiatan (presentasi kemajuan proyek), dan diakhir kegiatan proyek (presentasi hasil). Di sisi lain, siswa selalu melaporkan semua aktivitasnya melalui google form untuk dianalisis oleh guru. 
Kesadaran metakognitif merupakan variabel yang diukur pada penelitian ini. Metacognitive Awareness Inventory (MAI) yang dikembangkan oleh Schraw dan Dennison (Schraw \& Dennison, 1994b) digunakan sebagai instrumen pengumpulan data. Instrumen ini tersusun atas 52 item soal yang dalam delapan komponen metakognisi, yaitu: 1) Pengetahuan Deklaratif (PD); 2) Pengetahuan Prosedural (PP); 3) Pengetahuan Kondisional (PK); 4) Rencana (R); 5) Strategi Manajemen Informasi (SMI); 6) Monitoring Komprehensif (MK); 7) Strategi Debugging (SD); dan 8) Evaluasi (E). Seluruh item terdiri atas skala Likert dengan skala 1-5. Pendistribusian instrumen didistribusikan langsung kepada subjek penelitian. Siswa diberi kesempatan untuk melengkapi kuesioner tersebut selama 2 x 45 menit.

Tabel 1. Kategori level metakognisi

\begin{tabular}{cc}
\hline Skor & Kategori \\
\hline $86-100$ & Sangat Bagus \\
$76-85$ & Bagus \\
$60-75$ & Cukup \\
$55-59$ & Rendah \\
$0-54$ & Sangat Rendah \\
\hline
\end{tabular}

Setelah data terkumpul, analisis data dilakukan. Analisis data meliputi perhitungan persentase, rerata, dan standard deviation. Berbagai analisis statistik deskriptif tersebut ditujuakn untuk mengungkap sebaran level kesadaran metakognitif siswa, mengidentifikasi profil siswa di setiap komponen metakognisi, serta mengidentifikasi indikator kesadaran metakognitif yang paling optimal dan paling minimal dicapai oleh siswa. Rerata yang diperoleh kemudian dicocokkan dengan kategori level metakognisi berdasarkan penelitian terdahulu (Fauzi \& Sa'diyah, 2019) yang disajikan di Tabel 1. Selain itu, uji korelasi menggunakan Pearson Product Moment digunakan untuk menganalisis keberadaan hubungan tiap komponen metakognisi.

Ada satu informasi yang terlompati di metode penelitian ini adalah bagaimana/ prosedur guru memadukan CS dengan PjBL. Boleh digambar dengan diagram.

\section{HASIL DAN PEMBAHASAN}

Siswa berkemampuan akademik tinggi diindikasikan memiliki level kesadaran metakognitif yang baik (Abdellah, 2015). Berdasarkan hasil penelitian ini mayoritas siswa memiliki kesadaran metakognitif dengan kategori "cukup" (40\%) dan "baik" (40\%), sedangkan sisanya berkategori "sangat baik" (20\%). Secara lebih detail, sebaran level kesadaran metakognitif siswa disajikan di Gambar 1. Baiknya level kesadaran metakognitif siswa dalam penelitian ini sejalan dengan beberapa studi terdahulu yang turut mengkaji level metakognisi peserta didik di Indonesia. Beberapa penelitian tersebut, antara lain penelitian yang melibatkan siswa SMA di kota lain (Amin \& Sukestiyarno, 2015) maupun mahasiswa di perguruan tinggi (Erlin \& Fitriani, 2019). 


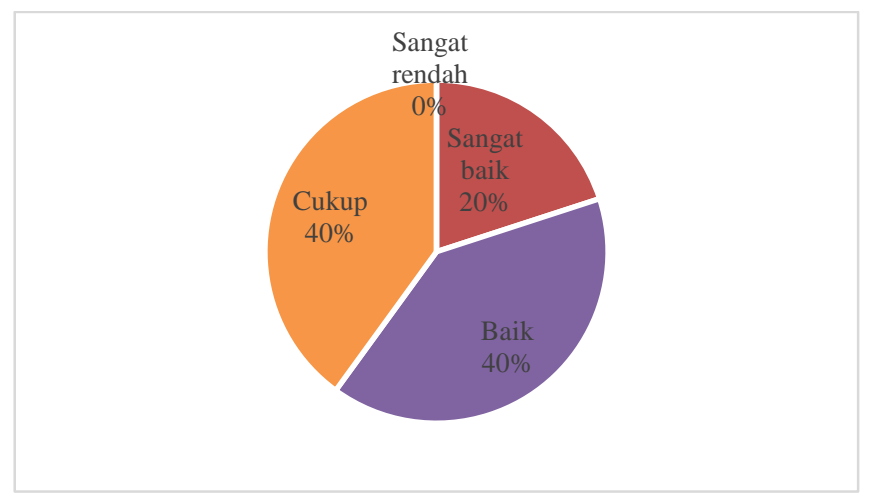

\section{Gambar 1. Profil kesadaran metakognitif siswa}

Selanjutnya, penelitian ini juga menginformasikan bahwa terdapat variasi level metakognisi antara satu komponen metakognisi dengan komponen lainnya. Secara umum, satu komponen metakognisi tergolong "cukup", enam komponen tergolong "baik", sedangkan satu komponen lainnya berkategori "sangat baik". Dari kedelapan komponen tersebut, evaluasi dan strategi debugging merupakan dua komponen metakognsi dengan capaian tertinggi. Secara lebih detail, variasi level komponen metakognisi yang diperoleh dalam penelitian ini disajikan di Gambar 2.

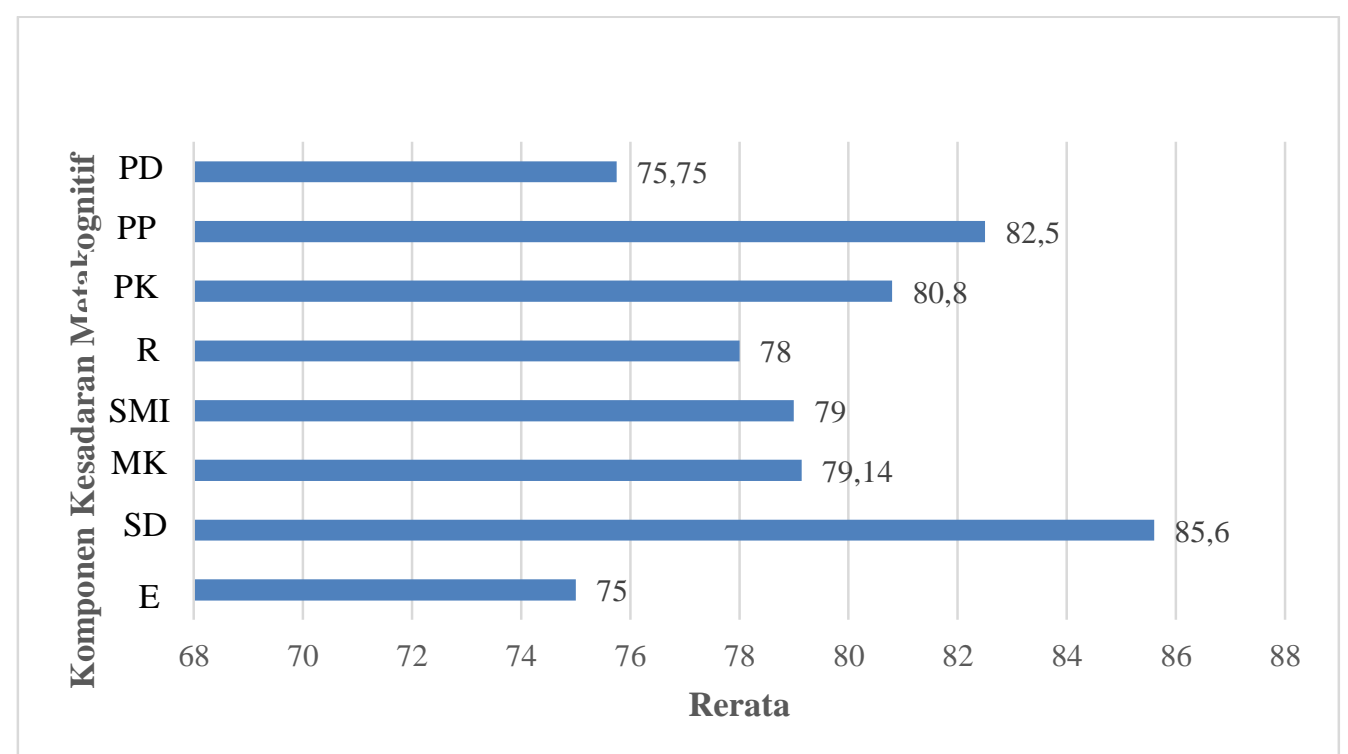

Gambar 2. Profil kesadaran metakognitif siswa di setiap komponen

Strategi debugging merupakan salah satu komponen dalam regulasi domain kognisi. Strategi debugging dilakukan ketika seorang siswa memperbaiki tingkat pemahaman mereka dan performa mereka selama belajar (Schraw \& Dennison, 1994a). Siswa dengan strategi debugging yang baik akan menyadari apa yang akan mereka lakukan ketika mereka kurang paham terhadap konsep yang semuanya dibuat. Di sisi lain, evaluasi juga merupakan komponen yang masuk ke dalam pengaturan domain kognisi. Kemampuan evaluasi siswa untuk menganalisis keefektifan strategi dan cara belajar mereka setelah mereka mempelajari topik tertentu (Schraw \& Dennison, 1994a). Evaluasi juga merupakan implementasi dari kegiatan refleksi yang dilakukan oleh siswa. 
Meski setiap komponen metakognisi memiliki level yang bervariasi, hasil uji Pearson menginformasikan bahwa mayoritas setiap komponen kesadaran metakognitif memiliki korelasi yang signifikan satu sama lain. Rangkuman hasil uji korelasi tersebut disajikan di Tabel 2. Adanya korelasi signifikan antara satu komponen dengan komponen lain menandakan bahwa peningkatan salah satu komponen metakognisi akan mampu mempengaruhi komponen metakognisi lainnya. Adanya korelasi signifikan di setiap komponen pun dapat dijadikan dasar bahwa komponen-komponen dalam regulasi kognisi memiliki hubungan kuat dengan domain pengetahuan tentang kognisi. Sebagaimana yang telah diketahui, perencanaan, manajemen system informasi, monitoring komprehensif, debugging strategies, dan evaluasi merupakan komponen-komponen dalam regulasi kognisi. Di sisi lain deklarasi, prosedural, dan pengetahuan kondisional merupakan tiga komponen dalam pengetahuan kognitif.

Tabel 2. Hasil Uji Pearson

\begin{tabular}{ccccccccc}
\hline & PD & PP & PK & R & SMI & MK & SD & E \\
\hline PD & 1 & $.677^{*}$ & $.758^{*}$ & 0.611 & $.755^{*}$ & $.815^{* *}$ & 0.439 & $.756^{*}$ \\
PP & $.677^{*}$ & 1 & 0.555 & $.792^{* *}$ & $.682^{*}$ & 0.594 & $.678^{*}$ & $.687^{*}$ \\
PK & $.758^{*}$ & 0.555 & 1 & 0.447 & 0.501 & 0.629 & 0.234 & 0.413 \\
R & 0.611 & $.792^{* *}$ & 0.447 & 1 & 0.500 & 0.409 & 0.530 & $.753^{*}$ \\
SMI & $.755^{*}$ & $.682^{*}$ & 0.501 & 0.500 & 1 & $.833^{* *}$ & 0.351 & $.722^{*}$ \\
MK & $.815^{* *}$ & 0.594 & 0.629 & 0.409 & $.833^{* *}$ & 1 & 0.206 & $.639^{*}$ \\
SD & 0.439 & $.678^{*}$ & 0.234 & 0.530 & 0.351 & 0.206 & 1 & 0.481 \\
E & $.756^{*}$ & $.687^{*}$ & 0.413 & $.753^{*}$ & $.722^{*}$ & $.639^{*}$ & 0.481 & 1 \\
\hline
\end{tabular}

*. Korelasi signifikan pada level 0,05.

**. Korelasi signifikan pada level 0,01.

Pemberdayaan kesadaran metakognitif merupakan salah satu upaya peningkatan kualitas pembelajaran (Beran, Brandl, Perner, \& Proust, 2012; Miller, 2017). Hasil penelitian ini menunjukkan bahwa pembelajaran cooperative script yang dipadu dengan PjBL mampu memberdayakan kesadaran metakognitif siswa SMA dengan baik. Oleh karena itu, penggunaan bentuk pembelajaran inovatif seperti pembelajaran yang diterapkan pada penelitian ini direkomendasikan diimplementasikan di berbagai pembelajaran di tingkat sekolah menengah.

\section{SIMPULAN}

Hasil penelitian ini menginformasikan bahwa kesadaran metakognitif siswa berkemampuan akademik tinggi mayoritas cukup memuaskan. Dari kedelapan komponen metakognisi yang dikaji, debugging strategies dan evaluation merupakan komponen keasadaran metakognitif yang capaiannya terrendah. Meski memiliki capaian rerata yang berbeda, hampir seluruh komponen metakognisi disimpulkan memiliki hubungan yang signifikan satu sama lain. Berkaitan dengan hasil penelitian yang diperoleh, pengimplementasia pembelajaran modifikasi CS yang dipadukan oleh Hybrid-PjBl direkomendasikan diterapkan di berbagai pembelajaran biologi karena manfaatnya dalam memberdayakan kesadaran metakognitif siswa.

\section{DAFTAR PUSTAKA}

Abdellah, R. (2015). Metacognitive awareness and its relation to academic achievement and teaching performance of pre-service female teachers in 
Ajman University in UAE. In Procedia - Social and Behavioral Sciences (Vol. 174, pp. 560-567). Elsevier B.V. https://doi.org/10.1016/j.sbspro.2015.01.707

Adnan, \& Bahri, A. (2018). Beyond effective teaching: Enhancing students' metacognitive skill through guided inquiry. In Journal of Physics: Conference Series (Vol. 954, p. 012022). https://doi.org/10.1088/17426596/954/1/012022

Amin, I., \& Sukestiyarno, Y. L. (2015). Analysis metacognitive skills on learning mathematics in high school. International Journal of Education and Research, 3(3), 213-222. Retrieved from http://www.ijern.com/journal/2015/March2015/18.pdf

Antika, R. N., \& Nawawi, S. (2017). Pengaruh model project based learning pada mata kuliah seminar terhadap keterampilan berpikir kreatif mahasiswa. JPBI (Jurnal Pendidikan Biologi Indonesia), 3(1), 72-79. Retrieved from http://ejournal.umm.ac.id/index.php/jpbi/article/download/3905/4609

Bell, S. (2010). Project-Based Learning for the 21st Century: skills for the future. The Clearing House: A Journal of Educational Strategies, Issues and Ideas, 83(2), 39-3. https://doi.org/10.1080/00098650903505415

Beran, M. J., Brandl, J. L., Perner, J., \& Proust, J. (2012). Foundations of metacognition. Oxford: Oxford University Press. Retrieved from https://psycnet.apa.org/record/2012-29672-000

Chauhan, A., \& Singh, N. (2014). Metacognition: A conceptual framework. International Journal of Education and Psychological Research (IJEPR), 3(3), 21-22. Retrieved from http://ijepr.org/doc/V3_Is3_Oct14/ij4.pdf

Colbert, C. Y., Graham, L., West, C., White, B. A., Arroliga, A. C., Myers, J. D., Clark, J. (2015). Teaching metacognitive skills: Helping your physician trainees in the quest to 'know what they don't know.' The American Journal of Medicine, 128(3), 318-324. https://doi.org/10.1016/j.amjmed.2014.11.001

Darmawan, E., Brasilita, Y., Zubaidah, S., \& Saptasari, M. (2018). Enhancing metacognitive skills of students with different gender using simas eric learning model at state senior high school 6 Malang. BIOSFER: Jurnal Pendidikan Biologi (BIOSFERJPB), 11(1), 47-56. https://doi.org/10.21009/biosferjpb.111.5

Diella, D., \& Ardiansyah, R. (2017). The correlation of metacognition with critical thinking skills of grade XI students on human excretion system concept. Jurnal Penelitian Dan Pembelajaran IPA, 3(2), 134-142. https://doi.org/10.30870/jppi.v3i2.2576

Erlin, E., \& Fitriani, A. (2019). Profile metacognitive awareness of biology education students in microbiology course. In Journal of Physics: Conference Series (Vol. 1157). https://doi.org/10.1088/1742-6596/1157/2/022066

Fauzi, A., \& Sa'diyah, W. (2019). The metacognition of pre-service biology teachers: Awareness, skills, understanding, and practices. In Advances in Social Science, Education and Humanities Research (Vol. 349, pp. 27-32). Atlantis Press. Retrieved from https://www.atlantis-press.com/ proceedings/iccd-19/125919010

Fini, E. H., Awadallah, F., Parast, M. M., \& Abu-Lebdeh, T. (2018). The impact of project-based learning on improving student learning outcomes of sustainability concepts in transportation engineering courses. European Journal of Engineering Education, 43(3), 473-488. https://doi.org/10.1080/ 03043797.2017.1393045 
Haryani, S., Masfufah, Wijayati, N., \& Kurniawan, C. (2018). Improvement of metacognitive skills and students' reasoning ability through problem-based learning. Journal of Physics: Conference Series, 983(1). https://doi.org/10.1088/ 1742-6596/983/1/012174

Holubova, R. (2008). Effective teaching methods - Project-based learning in physics. US-China Education Review, 5(12), 27-36. Retrieved from http://files.eric.ed.gov/fulltext/ED504949.pdf

Husamah. (2015). Blended project based learning: Metacognitive awareness of biology education new students. Journal of Education and Learning, 9(4), 274-281. https://doi.org/10.11591/edulearn.v9.i4.2121

Jankowski, T., \& Holas, P. (2014). Metacognitive model of mindfulness. Consciousness and Cognition, 28(1), 64-80. https://doi.org/10.1016 /j.concog.2014.06.005

Kokotsaki, D., Menzies, V., \& Wiggins, A. (2016). Project-based learning: A review of the literature. Improving Schools, 19(3), 267-277. https://doi.org/10.1177/1365480216659733

Miller, T. M. (2017). Measurement, theory, and current issues in metacognition: An overview. ACS Symposium Series, 1269, 1-15. https://doi.org/10.1021/bk2017-1269.ch001

Millis, B. J. (2016). Using metacognition to promote learning. IDEA Paper, 63(December), 1-9. Retrieved from http://www.ideaedu.org/Portals/0/ Uploads/Documents/IDEA Papers/IDEA Papers/PaperIDEA_63.pdf

Movahedzadeh, F., Patwell, R., Rieker, J. E., \& Gonzalez, T. (2012). Project-based learning to promote effective learning in biotechnology courses. Education Research International, 2012, 1-8. https://doi.org/10.1155/2012/536024

Nurajizah, U., Windyariani, S., \& Setiono, S. (2018). Improving students' metacognitive awareness through implementing learning journal. Jurnal Pendidikan Biologi Indonesia, 4(2), 105-112. https://doi.org/10.22219/jpbi. v4i2.5788

Patterson, J. (2011). Metacognitive skills. In Encyclopedia of Clinical Neuropsychology (Vol. 28, pp. 1583-1584). New York, NY: Springer New York. https://doi.org/10.1007/978-0-387-79948-3_897

Pavkov-Hrvojevic, M., Obadovic, D. Ž., Cvjeticanin, S., \& Bogdanovic, I. (2016). Fostering pimary school students' metacognition using project-based learning. In The Eurasia Proceedings of Educational \& Social Sciences (Vol. 4, pp. 123-126). Retrieved from http://dergipark.gov.tr/download/articlefile/332252

Pedone, F. (2014). How to improve metacognition in primary school. In Proceedings of INTED2014 Conference (pp. 1688-1698). Valencia. Retrieved from https://core.ac.uk/download/pdf/53290303.pdf

Ramadani, S. D., Fauzi, A., Sukmawati, I., \& Corebima, A. D. (2015). Perbandingan potensi strategi pembelajaran cooperative script dan reciprocal teaching dalam memberdayakan keterampilan metakognitif, hasil belajar Biologi, dan retensi siswa SMA. In Proceedings of the 2nd Seminar \& Workshop Nasional Biologi, IPA, dan Pembelajarannya FMIPA UM (pp. 655-661). Malang: Biologi FMIPA UM.

Rambely, A. S., Ahmad, R. R., Majid, N., M-Suradi, N. R., Din, U. K. S., ARahman, I., ... Abu-Hanifah, S. (2013). Project-based activity: Root of research and creative thinking. International Education Studies, 6(6), 66-71. 
https://doi.org/10.5539/ies.v6n6p8

Schraw, G., \& Dennison, R. S. (1994a). Assesing Metacognitive Awareness. Contemporary Educational Pschology, 19, 460-475. https://doi.org/10.1006/ceps.1994.1033

Schraw, G., \& Dennison, R. S. (1994b). Assessing metacognitive awareness. Contemporary Educational Psychology, 19(4), 460-475. https://doi.org/10.1006/ceps.1994.1033

Smith, A. K., Black, S., \& Hooper, L. M. (2017). Metacognitive knowledge, skills, and awareness: A possible solution to enhancing academic achievement in African American adolescents. Urban Education, 1-15. https://doi.org/10.1177/0042085917714511

Susilo, J., Kartono, \& Mastur, Z. (2019). Analysis metacognition and communication mathematics in blended learning use google classroom. Unnes Journal of Mathematics Education Research, 8(1), 72-83. Retrieved from https://journal.unnes.ac.id/sju/index.php/ujmer/article/view/24825

Thomas, G. P. (2014). Metacognition and science learning. In Encyclopedia of Science Education. Springer. https://doi.org/10.1007/978-94-007-6165-0

Tjalla, A., \& Putriyani, M. F. (2018). Mathematics metacognitive skills of Papua's students in solving mathematics problems. Asian Social Science, 14(7), 14. https://doi.org/10.5539/ass.v14n7p14

Yanqun, Z. (2019). The significance and instruction of metacognition in continuing education. International Forum of Teaching and Studies, 15(1), 29-37.

Yanti, H., Distrik, I. W., \& Khasyyatillah, I. (2017). Profile of senior high school metacognitive ability in solving problems of abstraction on physics material. Jurnal Ilmiah Pendidikan Fisika Al-Biruni, 6(2), 241. https://doi.org/10.24042/jipfalbiruni.v6i2.2061

Yusnaeni, \& Corebima, A. D. (2017). Empowering students' metacognitive skills on sscs learning model integrated with metacognitive strategy. The International Journal of Social Sciences and Humanities Invention, 4(5), 3476-3481. https://doi.org/10.18535/ijsshi/v4i5.03 